\title{
Perspectiva de resultados falso-negativos no teste de RT-PCR quando real- izado tardiamente para o diagnóstico de Covid-19
}

Erivan de Souza Oliveira'

Marcela Feitosa Matos ${ }^{2}$

Arlandia Cristina Lima Nobre de Morais ${ }^{1}$

O surto ocasionado pelo SARS-CoV-2, responsável pela doença denominada de covid-19, foi relatada pela primeira vez em dezembro de 2019 em Wuhan, na China e atualmente é considerada um problema de saúde pública global [1-3]. Devido a rápida disseminação da doença e o grande número de casos confirmados e óbitos em diversos países, os governantes tiveram que desenvolver medidas para conter a pandemia $[1,4]$.

Até o momento, o teste considerado padrão-ouro para o diagnóstico final da covid-19 é a reação em cadeia da polimerase com transcrição reversa (RT-PCR) [5]. Rio [6] destaca que este teste é utilizado para verificar a presença de mRNAs, pré-mRNAs ou outros tipos de RNA, como os RNAs não codificadores.

De acordo com Xie et al. [7] os pacientes com provável infecção por SARS-CoV-2 podem apresentar resultados iniciais negativos na RT-PCR, por diversas razões, mas principalmente pela extração inadequada de ácido nucleico e a insuficiência de material celular para a detecção do vírus. Ressalta-se que ainda não se sabe o intervalo dos níveis virais na covid-19 e o tempo ideal para a realizar a coleta do material [8-10].

No estudo realizado por Li et al. [11] foi relatado dois casos de pacientes que apresentavam sintomas de covid-19 e após a realização da RT-PCR foram considerados negativos. Entretanto, após a repetição do teste os pacientes foram diagnosticados com covid-19.
Esses autores reportam ainda que os erros laboratoriais, a precisão do teste, a coinfecção e a oscilação da carga viral podem interferir no resultado final.

$\mathrm{Na}$ pesquisa realizada por Xie et al. [8] foi constatado que dos 167 pacientes que foram avaliados, 5 deles receberam o resultado negativo para covid-19 na RT-PCR, apesar dos pacientes apresentarem quadro de pneumonia viral confirmadas através da Tomografia Computadorizada (TC) de tórax. No entanto, após a repetição do teste os pacientes receberam o diagnóstico de covid-19 e foram isolados para o tratamento.

Hao et al. [12] relataram em seu estudo o caso de um paciente com suspeita de covid-19 que, após a realização de dois testes de RT-PCR o resultado foi negativo e apesar da presença de uma leve opacidade em vidro fosco no segmento apical do lobo superior direito observado na TC de tórax, o paciente recebeu alta hospitalar. Porém, devido aos sintomas recorrentes de febre, tosse seca e fadiga, o paciente retornou ao hospital no mesmo dia da alta e repetiu o teste, e o resultado foi positivo para covid-19.

Neste contexto, cabe frisar que é indicado a realização da RT-PCR na fase aguda da doença entre o primeiro ao oitavo dia do surgimento dos sintomas para o diagnóstico da covid-19. Visto que após esse período ocorre o aumento da produção de anticorpos (inicialmente $\operatorname{lgM}$ ) e a diminuição da carga viral. Desta forma, o resultado

\footnotetext{
${ }^{1}$ Universidade de Fortaleza, Curso de Farmácia. Av. Washington Soares, 1321, Edson Queiroz, 60811-905, Fortaleza, CE, Brasil. Correspondência para: ES OLIVEIRA. E-mail: <erivan@edu.unifor.br>

2 Universidade Estadual do Ceará, Nutricionista. Fortaleza, CE, Brasil.

Q $\square \square \square$
} 
pode ser falso-negativo. Ressalta-se que na grande maioria dos pacientes o exame está sendo realizado após o período recomendado.

Al-Tawfiq \& Memish [10] destacaram que as amostras obtidas do trato respiratório superior para a pesquisa de SARS-CoV-2, apresentam um pico de carga viral após três dias do início dos sintomas da doença e que as amostras nasais possuem os maiores níveis de cargas virais [2]. Os mesmos enfatizam que os pacientes hospitalizados, precisam ser analisados com a combinação da RT-PCR e a TC do tórax para garantir um diagnóstico preciso.

Vale destacar que o material genético do SARSCoV-2 é formado por RNA, desta forma, na técnica de RT-PCR o RNA dos vírus é convertido em uma sequência complementar de DNA (cDNA) por transcriptases reversas e posteriormente ocorre a amplificação do cDNA recémsintetizado por procedimentos padrão de PCR para realizar a identificação do vírus [13-15].

Yan et al. [16] relatou dois casos suspeitos de covid-19, que inicialmente foram considerados como positivo para dengue através de testes rápidos para a pesquisa de anticorpos IgM e lgG contra o vírus. No entanto, devido os sintomas persistentes de febre, tosse, dispneia e piora da trombocitopenia, foi realizado o teste de RT-PCR a partir de um swab nasofaríngeo e o resultado foi positivo para covid-19. Desta forma, o diagnóstico inicial de dengue foi descartado. Vale salientar que os mesmos autores informam que os resultados sorológicos falso-positivos podem ocasionar sérias consequências para o paciente e a saúde pública.

De acordo com Hao et al. [12] um único resultado negativo de RT-PCR, não pode excluir a infecção causada pelo SARS-CoV-2 e se ocorrer divergências nos resultados é indicado a coleta de amostras do trato respiratório inferior (p. ex., lavado broncoalveolar e aspirados traqueais).

Hosoda et al. [17] destacou em seu estudo o caso de uma paciente de 81 anos de idade, que previamente teve o resultado negativo para covid-19 através da técnica de RT-PCR realizada com as amostras de orofaringe. Contudo, após a realização do teste com amostras de fezes ela foi diagnosticada com enterocolite secundária à infecção por SARS-CoV-2. Durante o período de internação a paciente realizou diversos testes de RT-PCR com amostras de fezes e o resultado foi negativo para SARS-CoV-2 a partir do $16^{\circ}$ dia de hospitalização.

Neste contexto, é de suma importância que os resultados obtidos através da RT-PCR sejam interpretados de forma correta, pois a identificação precoce, diagnóstico correto e a realização da quarentena (especialmente na fase inicial dos sintomas), são medidas essenciais para diminuir a transmissão da doença [18].

Ainda que os resultados laboratoriais demorem (visto a demanda de testes a serem realizados), é preciso manter o paciente em isolamento até que seja descartado a possiblidade de covid-19.

Oliveira \& Morais [19] ressalta que é preciso identificar um possível marcador para avaliar o quadro clínico dos pacientes em tratamento e apesar do diagnóstico imediato e o isolamento dos pacientes sejam as principais medidas do controle desse vírus, deve-se avaliar a hipótese da elaboração de outras estratégias que possam conter a pandemia existente no país.

É possível observar que diversas publicações destacam a possibilidade de falso-negativos no teste de RT-PCR. Entretanto, até à presente data é indicado a realização do teste de RT-PCR para o diagnóstico definitivo da covid-19. Recomenda-se, portanto, ser realizado precocemente para que o resultado seja confiável.

\section{REFERÊNCIAS}

1. Liu, J., Cao, R., Xu, M., Mang, X., Zhang, H., Hu, H., et al. Hydroxychloroquine, a less toxic derivative of chloroquine, is effective in inhibiting SARS-CoV-2 infection in vitro. Cell Discovery, 2020; 6:16. doi: 10.1038/s41421-020-0156-0

2. Zou L, Ruan F, Huang M, Liang L, Huang H, Hong Z, et al. Positive RT-PCR Test Results in Patients Recovered From COVID-19. SARS-CoV-2 Viral Load in Upper Respiratory Specimens of Infected Patients. New England J Med. 2020. doi: 10.1056/NEJMc2001737

3. Lana RM, Coelho FC, Gomes MFC, Cruz OG, Bastos LS, Villela DAM, Codeço CT. Emergência do novo coronavírus (SARS-CoV-2) e o papel de uma vigilância nacional em saúde oportuna e efetiva. Cad. Saúde Pública. 2020;36(3):e00019620. doi: $10.1590 / 0102-311 \times 00019620$

4. Berger ZD, Evans NG, Phelan AL, Silverman RD. Covid-19: control measures must be equitable and inclusive. BMJ. 2020;368:m1141. 2020. doi: 10.1136/bmj.m1141

5. Araújo-Filho JAB, Sawamura MVY, Costa AN, Cerri GG, Nomura CH. Pneumonia por COVID-19: qual o papel da imagem no diagnóstico?. 
J Bras Pneumol. 2020;46(2):e20200114. 2020. doi: $10.36416 / 1806-3756 /$ e20200114

6. Rio DC. Reverse Transcription-Polymerase Chain Reaction. Cold Spring Harb Protoc. 2020. doi:10.1101/pdb.prot080887

7. Xie X, Zhong Z, Zhao W, Zheng C, Wang F, Liu J. Chest CT for Typical 2019-nCoV Pneumonia: Relationship to Negative RT-PCR Testing. Radiology. 2020. doi: 10.1148/radiol.2020200343

8. Lan L, Xu D, Ye G, Xia C, Wang S, Li Y, et al. Positive RTPCR Test Results in Patients Recovered From COVID-19. Research Letter. 2020. doi:10.1001/jama.2020.2783

9. Sociedade Brasileira de Análises Clínicas (SBAC) [homepage na internet]. Teste rápido da Covid-19: falsos negativos [acesso em 09 de abril 2020]. Disponível em: http://www.sbac.org.br/blog/2020/04/02/ teste-rapido-da-covid-19-falsos-negativos/

10. Al-Tawfiq JA, Memish ZA. Diagnosis of SARSCoV-2 Infection based on CT scan vs. RT-PCR: Reflecting on Experience from MERS-CoV. J Hospital Infection. 2020. doi: 10.1016/j.jhin.2020.03.001

11.LiD, WangD, Dong J, Wang N, Huang H, XuH, XiaC. Roleof Deep-Learning-Based CT Diagnosis and Insights from Two Cases. Korean J Radiol. 2020. doi: 10.3348/kjr.2020.0146

12. Hao Q, Wu H, Wang G. Difficulties in False Negative Diagnosis of Coronavirus Disease 2019: A Case Report. Research Square. 2020. doi: 10.21203/rs.3.rs-17319/v1

13. Brasil. Ministério da Saúde [homepage na internet]. Reação em cadeia da polimerase-transcriptase reversa (RT$P C R$ ) qualitativa e quantitativa (RT-qPCR) e Hibridização in situ (ISH) para o diagnóstico e monitoramento da Leucemia Mieloide Crônica (LMC) e da Leucemia Linfoblástica Aguda cromossoma Philadelphia positivo $($ LLA Ph+) [acesso em 09 de abril 2020]. Disponível em: http://conitec.gov.br/images/Relatorios/2019/ Relatorio_ReacaoCadeiaPolimerase_LeucemiasPh.pdf

14. Barrocas EN, Machado JC, Figueira AR, Souza $R M$, Ishida $A K N$, Zacaroni $A B$, et al. Uso de técnicas moleculares para diagnose de patógenos em sementes. Informe Agropecuário, 2009; 30(253): 24-32.
15. Sociedade Brasileira de Análises Clínicas (SBAC) [homepage na internet]. Diagnóstico laboratorial do coronavírus (SARS-CoV-2) causador da COVID-19 [acesso em 09 de abril 2020]. Disponível em: http://www. sbac.org.br/blog/2020/03/30/diagnostico-laboratorialdo-coronavirus-sars-cov-2-causador-da-covid-19/

16. Yan G, Lee CK, Lam LTM, Yan B, Chua YX, Lim AYN, et al. Covert COVID-19 and falsepositive dengue serology in Singapore. Lancet. 2020. doi: 10.1016/S1473-3099(20)30158-4

17. Hosoda T, Sakamoto M, Shimizu $H$, Okabe N. ARS-CoV-2 enterocolitis with persisting to excrete the virus for about two weeks after recovering from diarrhea: A case report. Infection Control \& Hospital Epidemiology. 2020. doi: 10.1017/ice.2020.87

18. Yang W, Yan F. Patients with RT-PCR Confirmed COVID-19 and Normal Chest CT. Radiology. 2020;200702. 2020. doi: 10.1148/radiol.2020200702

19. Oliveira ES, Morais ACLN. COVID-19: uma pandemia que alerta à população. IAJMH. 2020;3:e202003008. doi: 10.31005/iajmh.v3i0.80 